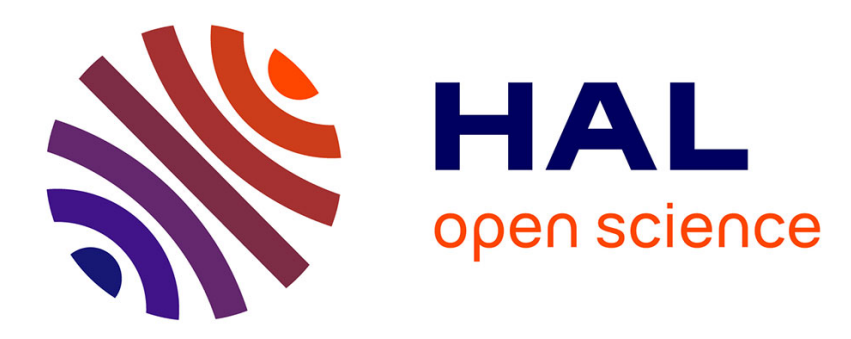

\title{
Plasticity of the spinodally decomposing Ni-11.8 at.\% Ti alloy
}

M. Lambrigger

\section{To cite this version:}

M. Lambrigger. Plasticity of the spinodally decomposing Ni-11.8 at.\% Ti alloy. Journal de Physique IV Proceedings, 1993, 03 (C7), pp.C7-2015-C7-2020. 10.1051/jp4:19937321 · jpa-00251967

\section{HAL Id: jpa-00251967 https://hal.science/jpa-00251967}

Submitted on 1 Jan 1993

HAL is a multi-disciplinary open access archive for the deposit and dissemination of scientific research documents, whether they are published or not. The documents may come from teaching and research institutions in France or abroad, or from public or private research centers.
L'archive ouverte pluridisciplinaire $\mathbf{H A L}$, est destinée au dépôt et à la diffusion de documents scientifiques de niveau recherche, publiés ou non, émanant des établissements d'enseignement et de recherche français ou étrangers, des laboratoires publics ou privés. 


\title{
Plasticity of the spinodally decomposing Ni-11.8 at.\% Ti alloy
}

\author{
M. LAMBRIGGER
}

Institut für Angewandte Physik, ETH Zürich, 8093 Zürich, Switzerland and

Im Struppen 12, 8048 Zürich, Switzerland

\begin{abstract}
The spinodal decomposition of supersaturated $\mathrm{Ni}-11.8$ at.\% Ti single crystals (fcc structure) was studied during ageing at 853 and $1073 \mathrm{~K}$. All the samples were homogenised at $1423 \mathrm{~K}$ and then waterquenched to room temperature prior to ageing. The quenched samples were found consisting of short-range ordered matrix and slightly L12 - ordered Ti-rich domains. During the first sixty hours of ageing at $853 \mathrm{~K}$, a "metastable situation" was found, where the microstructure of the samples did not change very much. Between sixty and five hundred hours of ageing, concentration waves developed, which grew in amplitude and wavelength with increasing ageing time. Later on, coarsening started, leading to metastable $\gamma^{\prime}$ particles (L12 - structure), which began to become incoherent after $4000 \mathrm{~h}$ of ageing. The kinetics of $\mathrm{Ni}$ - 11.8 at.\% Ti single crystals at $1073 \mathrm{~K}$ were investigated in order to study the phase transformation to the stable ? - Ni3Ti phase (D024 - structure). Not fully $\mathrm{D}_{24} 4$ - ordered nuclei with $\mathrm{ABAC}$ stacking sequences were observed. Furthermore, defective stacking sequences, derived from the $A B A C$ stacking sequence, were found to occur frequently. A mechanism based on Shockley partial dislocations is suggested for the transformation of the fcc structure to the ABAC stacking sequence of the $\mathrm{D} 024$ - structure.

The mechanical properties of quenched and aged $\mathrm{Ni}-11.8$ at.\% $\mathrm{Ti}$ single crystals were investigated by compressive, tensile and fatigue tests performed at room temperature. The quenched specimens showed planar glide in all types of tests, and even strain bursts, which are typical for short-range ordered single crystals, were recorded during fatigue tests. Superdislocations and dislocation pile-ups were observed by Transmission electron microscopy in quenched samples, which were deformed in compression. The samples aged at $853 \mathrm{~K}$, which were consisting of a microstructure containing concentration waves, showed a very localised deformation behaviour. Instabilities were observed in compressive tests, and in tensile and fatigue tests a low ductility was noted. In all types of tests a very high yield strength was measured. It may be assumed, that these special mechanical properties are the result of the tendency to nucleate the stable $\eta$ phase. The dislocation structure of samples consisting of a microstructure with concentration waves, was found to be dominated by regularly dissociated $a / 2<110>$ dislocations. This dissociation into Shockley partial dislocations takes place in the Ti-rich domains. The dislocations may be considered to act as microprobes which are very sensitive to the Ti concentration.

A model based on planar slip is presented, which describes the formation of defective microtwins, i.e. $A B A C$ stacking sequences containing $a / 2<110>$ dislocation segments, out of regularly split, paired dislocations under an external stress in a microstructure consisting of concentration waves. These microtwins are the basic elements of the ABAC stacking sequence of the stable $\eta$ phase.
\end{abstract}




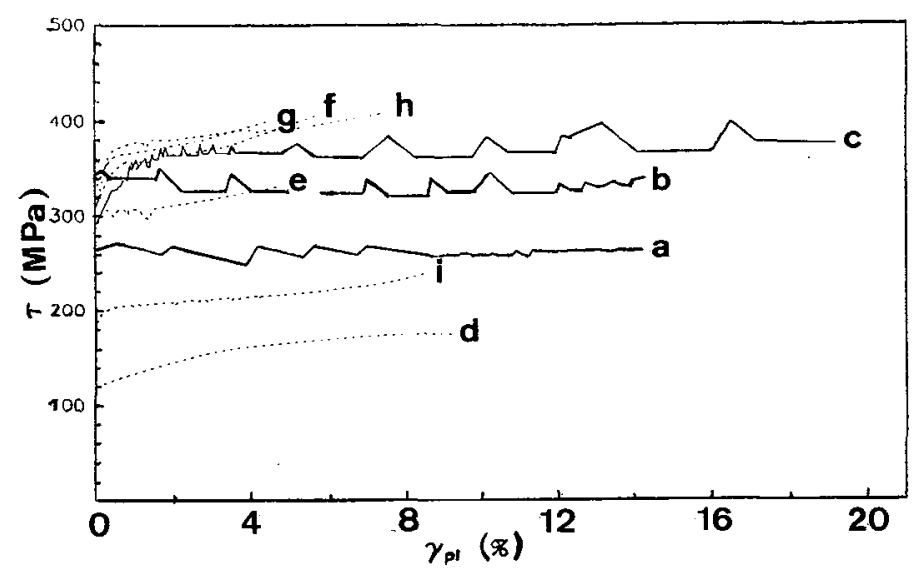

Figure 1. Full lines: Samples deformed in uniaxial compression and aged for a) 62.5 b) 500 and c) 1000 hours at $853 \mathrm{~K}$ (measured at room temperature, crystal axis parallel to [234], length-to-diameter ratio of the samples about 1.8). Spotted lines: Samples deformed in uniaxial compression and aged for d) 0 e) $62.5 \mathrm{f}) 250 \mathrm{~g}$ ) 500 h) 1000 and i) 2000 hours at $853 \mathrm{~K}$ (measured at room temperature, crystal axis parailel to [124], length-to-diameter ratio of the samples about two).

\section{INTRODUCTION}

The decomposition of supersaturated $\mathrm{Ni}-12$ at.\% Ti alloys has been investigated at a wide range of temperatures. It has been shown, that a metastable miscibility gap exists approximately underneath $1200 \mathrm{~K}$. At ageing temperatures lower than about $853 \mathrm{~K}$, the decomposition starts with the formation of periodic concentration waves followed by metastable, coherent $\gamma^{\prime}$ particles with $\mathrm{L}_{2} 2$ - structure. The composition of these metastable precipitates is stated to be lower than the nominal concentration of the L12 - structure of 25 at.\% Ti [1,2]. The stable \% phase with D024 - structure is formed, for example, at $873 \mathrm{~K}$ after forty days [3,4]. At higher temperatures (around $1073 \mathrm{~K}$ ) the metastable $\gamma^{\prime}$ precipitates form fast; the phase transformation of parts of the matrix $\gamma$ (fcc structure) and of previously formed metastable $\gamma^{\prime}$ particles to the stable $\rangle$ phase begins after about four hours. The phase transformation from $\gamma$ to $\eta$ phase was first investigated by Mihalisin and Decker [5]. These authors report, that the $\eta$ phase, in some cases, nucleates at stacking faults in the $\gamma$ matrix and that cold-work increases the rate of transformation to $\eta$ by increasing the stacking fault density. Sass and Cohen [6] revealed the crystallographic nature of the stable 7 phase as a four-layer hexagonal, close-packed and ordered structure with stacking sequences ABAC.

\section{EXPERIMENTAL}

The Ni-11.8 at.\% $\mathrm{Ti}$ alloy was prepared by vacuum induction melting of nickel (99.99\%) and titanium $(99.9 \%$ ). Cylindrical rods were cast, and single crystals about $10 \mathrm{~cm}$ long and 5.5 $\mathrm{mm}$ in diameter were grown by electron-beam zone melting at a speed of about $0.5 \mathrm{~mm} / \mathrm{min}$. The operating pressure was always smaller than 10-5 mbar. The concentration gradient along the crystal axis was smaller than 0.05 at. $\% / \mathrm{cm}$. Single crystals with growth axes parallel to $[015],[\overline{1} 24],[\overline{1} 23]$ or $[\overline{2} 34]$ were used for compressive,tensile and fatigue tests. Cylindrical 

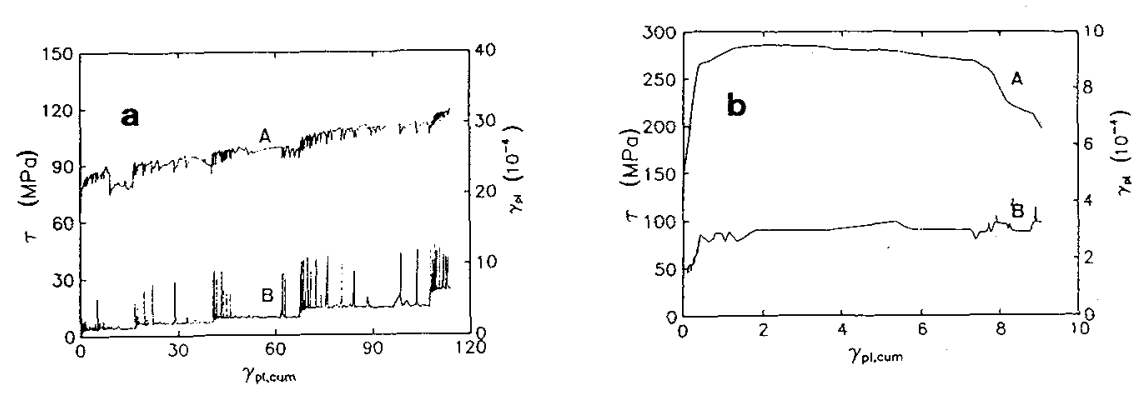

Figure 2. a) Cyclic hardening curve (A) from step tests of a quenched $\mathrm{Ni}-11.8$ at.\% Ti single crystal (measured at room temperature, crystal axis parallel to [123]). The plastic strain amplitude (B) is also displayed. b) Cyclic hardening curve (A) of a $\mathrm{Ni}-11.8$ at.\% Ti single crystal quenched and aged for 500 hours at $853 \mathrm{~K}$ (measured at room temperature, crystal axis parallel to [123]). The plastic strain amplitude (B) is also displayed.

rods 3 to $4 \mathrm{~mm}$ in diameter and 6 to $10 \mathrm{~mm}$ in length were cut by spark erosion. Cylindrical specimens with a length-to-diameter ratio between 1.8 and 3 were used for the uniaxial compressive tests. The samples were homogenised at $1423 \mathrm{~K}$ for $2 \mathrm{~h}$ in an evacuated quartz tube and then quenched into water. After a heat treatment at $853 \mathrm{~K}$ or $1073 \mathrm{~K}$ (in the case of the aged specimens) the samples were electropolished in a solution of $15 \mathrm{vol} \% \mathrm{H}_{2} \mathrm{SO}_{4}, 64$ vol. $\% \mathrm{H}_{3} \mathrm{PO}_{4}$ and water. In order to produce single crystalline tensile and fatigue samples, single crystalline cylinders about $3.5 \mathrm{~mm}$ in diameter and $10 \mathrm{~mm}$ in length were welded by butt welding (or soldering in the case of the quenched fatigue specimens) to cylindrical grips of Nimonic 75. The specimens were then homogenised, quenched and aged. After that, the specimens were ground with a corundum disk to final dimensions. The compressive tests were performed in a screw-driven machine, at a crosshead speed of $0.2 \mathrm{~mm} / \mathrm{min}$. The tensile tests were performed on a screw-driven machine with a constant strain rate of 0.0005 resp. 0.00005 $\mathrm{s}^{-1}$. The fatigue tests were performed on a hydraulic machine. These tests took place under plastic strain control by applying a sinusoidal load cycle of $3 \mathrm{~Hz}$ and a zero mean strain. The plastic strain amplitude was kept constant by controlling the total strain amplitude on the specimen. Hysteresis loops were continuously monitored. The microhardness measurements were performed on a commercial Leitz Durimet 2 instrument. Thin foils for TEM samples were thinned mechanically, dimpled and electropolished in a solution of $20 \mathrm{vol} \% \mathrm{HNO}_{3}$ in methanol at $223 \mathrm{~K}$ using a twin-jet apparatus. TEM was performed on a Jeol $200 \mathrm{CX}$ microscope operating at $200 \mathrm{kV}$.

\section{RESULTS}

The microstructure of quenched $\mathrm{Ni}-11.8$ at.\% $\mathrm{Ti}$ single crystal specimens, deformed in compression, is characterised by the presence of dislocation pile-ups and superdislocations, probably imposed by short-range order and long-range ordered domains. A moderate yield strength and a high ductility is measured in compressive (figure 1), tensile and fatigue tests of single crystalline specimens. Planar glide was observed in all these types of mechanical tests by surface investigations. In addition, strain bursts were recorded in fatigue tests (figure 2a), whose intensities were diminished by the presence of grain boundaries. This fatigue behaviour is common in short-range ordered alloys which show planar glide as $\mathrm{Cu}-\mathrm{Al}$ or $\mathrm{Ni}-\mathrm{Cr}[7,8]$.

The samples aged between 62.5 and and 1000 hours show serrated flow in compressive tests. The serrated flow is strongly influenced by the length-to-diameter ratio and the orientation of the single crystals (figure 1). Surface investigations indicate planar glide and strongly localised 

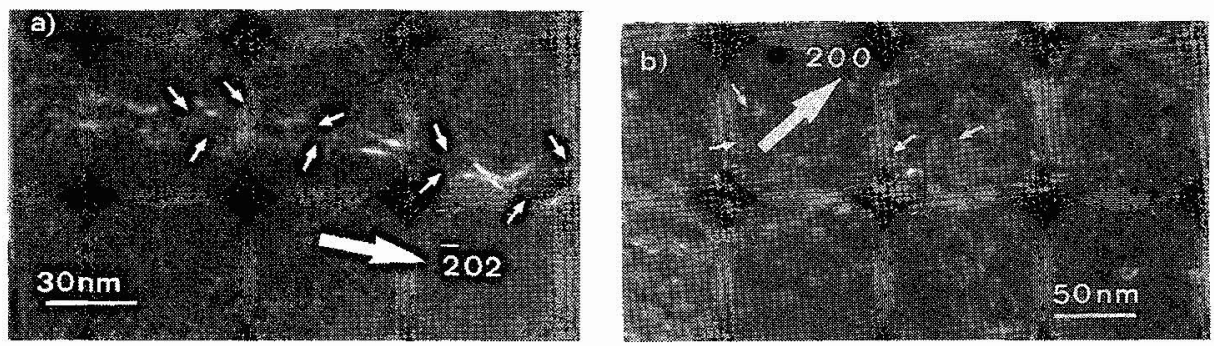

Figure 3. Weak-beam images of $\mathrm{Ni}-11.8$ at.\% Ti single crystals taken with a Transmission electron microscope at $200 \mathrm{kV}$. a) Single crystal aged for $250 \mathrm{~h}$ at $853 \mathrm{~K}$ and deformed at room temperature in compression (crystal axis parallel to [124]). Paired dislocations dissociated periodically into four Shockley partial dislocations are visible in the glide plane (see small arrows). The zone axis is parallel to [111]fcc and the diffraction vector $g=[\overline{202}]$ is parallel to the Burgers vectors of the undissociated parts of the dislocations. b) Single crystal aged for 500 hours at $853 \mathrm{~K}$ and deformed at room temperature in compression (crystal axis parallel to [234]). Accumulations of regularly dissociated dislocations are depicted. Line defects are marked with small arrows. The zone axis is parallel to [001] fcc and the diffraction vector is $\mathrm{g}=[200]$.

deformation. The samples aged for 500 hours at $853 \mathrm{~K}$ show a very high yield strength in tensile and compressive tests, but also a low ductility in tensile and fatigue tests (figure $2 \mathrm{~b}$ ). Single crystals deformed in tension, failed after about $10 \%$ plastic shear, if they were oriented for single glide (crystal axis parallel to [123]) and after about $3 \%$ plastic shear in double glide orientation (crystal axis parallel to [015]). The microstructure of the specimens aged between 62.5 and $500 \mathrm{~h}$ at $853 \mathrm{~K}$ mainly consist of periodical concentration waves in $\langle 100\rangle$ directions. The dislocation structure which developed during deformation in compressive tests, is dominated by regularly dissociated, paired dislocations whose periodicity correspond to the periodicity of the concentration waves of the microstructure. These dislocations act, therefore, as microprobes which are very sensitive to the Ti concentration (figures 3a,b). The observed dislocation type can be described as a superdislocation consisting of two identical a/ $2<110\rangle$ dislocations regularly split into two $a / 6<112>$ Shockley partial dislocations (SPDs) each. The dissociation takes place on the (111)fec glide planes in the Ti-rich domains, forming two complex stacking faults (CSFs) on both sides of an antiphase boundary (APB). In the regions where the dislocations split, i.e. in the Ti-rich domains, the width of the APB is small. The CSFs, however, are widely spread. This behaviour of the superdislocations can easily be explained, since the degree of $\mathrm{L}_{2}$ - ordering is probably increased in the Ti-rich region with respect to the Ti-poor domains and, therefore, also the APB energy. The CSF energy, however, is low in the Ti-enriched domains because of the tendency to transform to the hexagonal, stable phase. In polycrystals (grain diameter $\mathrm{d}=0.2 \mathrm{~mm}$ ), which were aged for $500 \mathrm{~h}$ at $853 \mathrm{~K}$ and deformed in fatigue, even pile-ups of regularly split dislocations were observed.

Between 1000 and $2000 \mathrm{~h}$ of ageing at $853 \mathrm{~K}$, the yield strength of the specimens considerably decreases. The serrated flow effect, observed during compressive tests also decreases (figure 1), indicating a less localised deformation. The microstructure after $2000 \mathrm{~h}$ of ageing consists of $\gamma^{\prime}$ particles which are less regular distributed than the Ti-rich domains in the samples aged for $500 \mathrm{~h}$ at $853 \mathrm{~K}$. Paired dislocations which cut the $\gamma^{\prime}$ particles during deformation are predominant in these samples. Therefore, the superdislocation type with regular splitting into SPDs must be favoured, if a regular distribution of Ti-rich obstacles is present with only small spacings among themselves and no sharp interfaces. Thus, it can be 

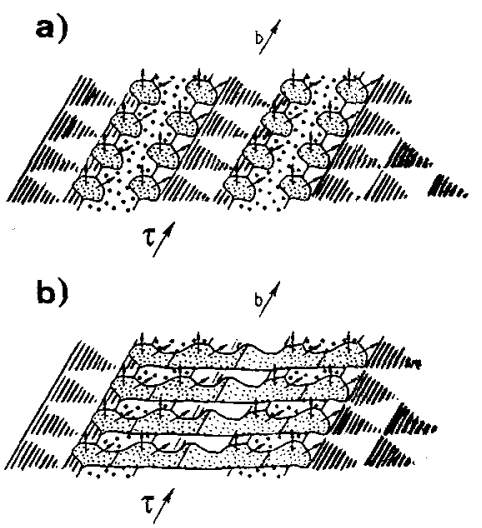

$$
\begin{aligned}
& \because:: \text { APS } \\
& \text { Ailu } \mathrm{L}_{3} \text { oroered } \\
& b p_{1}=0 / 6[214] \\
& -b p_{2}=0 / 6[\overline{1} \overline{1}] \\
& f \quad b=0 / 2 \text { [704] }
\end{aligned}
$$

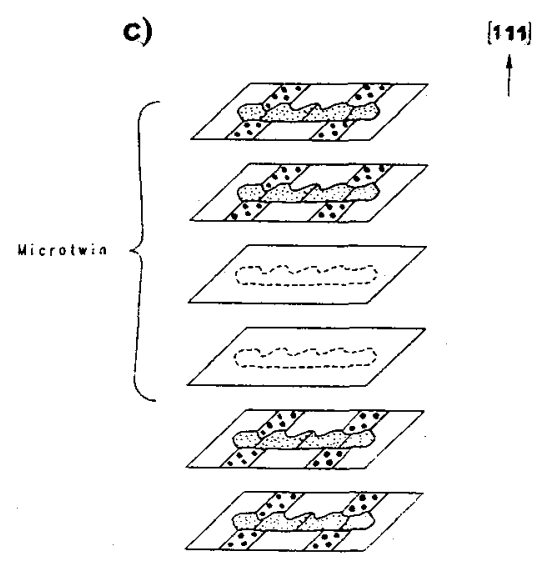

Figure 4. a) Periodically dissociated screw dislocations with Burgers vectors $b=a / 2[\overline{1} 01]$ and equal line senses are accumulated in the glide planes by planar glide. One glide plane is shown. b) Every Shockley partial dislocation (SPD) reacts under an external stress with the neighbouring SPD in its glide plane forming a/2[101] screw segments, which divide the complex stacking faults in different sections. c) Pairs of SPDs are operating on neighbouring (111)fcc planes and the following planes remain unchanged. Transformation blocks of four (111) fcc planes form a defective microtwin of the stable $\eta$ phase, i.e. an ABAC stacking sequence containing a/2[101] dislocation segments.

argued, that long-range interaction forces present in the microstructure consisting of concentration waves are responsible for the tendency to nucleate the stable phase via the dissociation of $\mathrm{a} / 2<110>$ dislocations in the Ti-rich domains. After $4000 \mathrm{~h}$ of ageing at $853 \mathrm{~K}$ the coherency limit of the $g^{\prime}$ particles is reached. The microhardness between 2000 and $4000 \mathrm{~h}$ of ageing, however, increases. Thus, cutting of $\gamma^{\prime}$ particles by paired dislocations is presumed to remain the predominant deformation mechanism after $4000 \mathrm{~h}$ of ageing as in the samples aged for $2000 \mathrm{~h}$ at $853 \mathrm{~K}$. However, a further ageing of the samples would probably lead to an Orowan mechanism and, consequently, to a second drop of the microhardness.

To determine the operating mechanism in the early stage of the phase formation, the kinetics at $1073 \mathrm{~K}$ were studied. The nucleation of $q$ plates was investigated after 4 and $24 \mathrm{~h}$ of ageing. The 7 nuclei were found to be not fully $\mathrm{DO}_{24}$ - ordered. Defective stacking sequences, derived from the ordinary ABAC stacking sequence of the $\eta$ phase, and ledges were observed quite often.

\section{DISCUSSION}

A complete transformation of the fcc lattice to the ABAC stacking sequence of the $\eta$ phase, maintaining full coherency with the nontransformed fcc lattice across densily packed planes, can be achieved by six Shockley partial dislocations (SPDs) operating on a unit of twelve (111)fcc planes. Pairs of SPDs are operating on neighbouring (111) fcc planes, and the following two (111)fec remain unchanged [9]. In this way transformation blocks of four (111)fec planes develop, which form a microtwin with an ABAC stacking sequence. 
In figures 4a-c a model is presented, which describes the formation of defective microtwins, i.e. $\mathrm{ABAC}$ stacking sequences containing $\mathrm{a} / 2<110>$ dislocation segments, out of regularly split, paired dislocations under an external stress in microstructures consisting of concentration waves. If periodically dissociated screw superdislocations, with Burgers vectors $b=a / 2[\overline{1} 01]$ and equal line senses, are accumulated in two neighbouring (111)fcc glide planes by planar glide under an external stress (as indicated in figure 4a) and if every Shockley partial dislocation (SPD) reacts under the back stress of the dislocation pile-ups with the neighbouring SPD in its glide plane (figure $4 \mathrm{~b}$ ), a highly localised deformation by forming small, defective microtwins could be produced (figure $4 \mathrm{c}$ ). These microtwins are the basic elements of the ABAC stacking of the stable $\eta$ phase. Since many $a / 2[101]$ dislocation segments are produced by the reactions of neighbouring SPDs (figures $4 a, b$ ), a high dislocation density should be present in the reacting (111) fcc planes of the microtwins (figure $4 \mathrm{c}$ ). Figure $3 \mathrm{~b}$ shows accumulations of regularly dissociated dislocations of a sample aged for $500 \mathrm{~h}$ at $853 \mathrm{~K}$ and deformed in compression. Stacking faults and line defects are visible which might be the result of the presence of defective microtwins.

The described model predicts the immobilisation of the active slip bands by the induced phase transformation, if the value of the applied shear stress and the density of the regularly split dislocations is high enough in the glide planes after a certain amount of planar glide. Thus, the observed serrations in stress-strain curves of compressive tests could be related to the softening by shearing of the Ti-rich domains and the sudden immobilisation of the active slip planes by dislocation reactions leading to defective microtwins. After the immobilisation of a slip band; an increased shear stress is necessary to activate glide in other regions of the specimens. The early failure of samples aged for $500 \mathrm{~h}$ at $853 \mathrm{~K}$ in tensile and fatigue tests, however, might be the result of a) positive normal stresses produced during these types of mechanical tests, $b$ ) the very localised deformation behaviour of the specimens and c) the high local density of defects (dislocation segments in the model) produced by the formation of defective microtwins. The much earlier failure of single crystals oriented for double glide in comparison with single crystals oriented for single glide in tensile tests, can thus be explained by the increased formation of microcracks, since the local accumulation of defects is strongly enhanced by double glide following the model.

\section{CONCLUSIONS}

The special mechanical properties of samples with a microstructure containing concentration waves are the result of a) planar glide, b) very localised deformation and c) the tendency to nucleate the stable $\eta$ phase by interactions of regularly dissociated dislocations. Defective structures derived from the $\mathrm{ABAC}$ stacking sequence of the stable $\eta$ phase were also observed during nucleation of stable $\eta$ plates at $1073 \mathrm{~K}$.

\section{REFERENCES}

1) BEN ISRAEL D.H. and FINE M.E., Acta Metall. 11, (1963), 1051.

2) CERRI A., SCHONFELD B. and KOSTORZ G., Phys. Rev. B $42,(1990), 958$.

3) HASHIMOTO K. and TSUJMOTO T., Trans. Nat. Res. Inst. Metals 18, (1976), 1.

4) HASHIMOTO K. and TSUIIMOTO T., Trans. J.I.M. 19, (1978), 77.

5) MIHALISIN J. R. and DECKER R.F., Trans. Met. Soc. AIME 218, (1960), 507.

6) SASS S.L. and COHEN J.B., Trans. Met. Soc. AIME 245, (1969), 153.

7) YAN B.D., CHENG S., BUCHINGER L., STANZL S. and LAIRD C., Mat. Sci. Engg. A $\underline{80},(1986), 129$.

8) WOLF K.; CALDERON H.A., VOGEL P., JUUL JENSEN D., KOSTORZ G., Low Cycle Fatigue and Elasto-Plastic Behaviour of Materials - 3, Elsevier Science Publishers Ltd., Barking, Essex, England (1992), 160.

9) LAMBRIGGER M., CALDERON H. and KOSTORZ G., Z. Metallkd. $\underline{83}$, (1992), 624. 